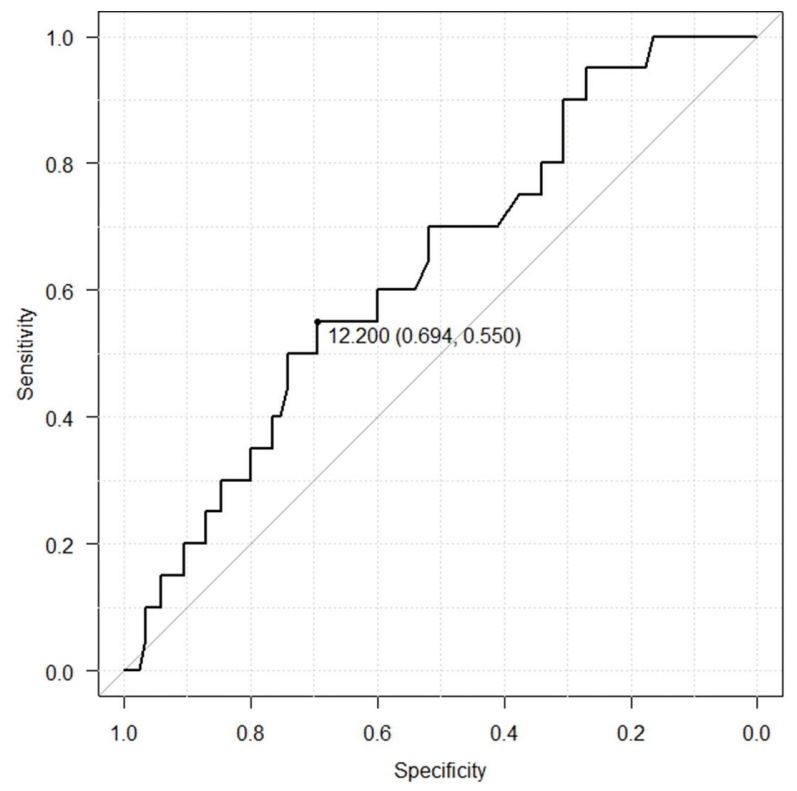

Abstract AB1003 - Figure 1

Conclusions: In this prospective study, DVT was detected in 2 patients on admission, 9 patients one day before surgery, and 9 patients one week after surgery. As DVT can occur at any moment, performing repeated Doppler ultrasound examinations in the perioperative period is useful for quickly detecting DVT, which can cause PE. As for the d-dimer level, its sensitivity and negative predictive value reached $100 \%$ at a cut-off level of $4.3 \mu \mathrm{g} / \mathrm{ml}$. Therefore, d-dimer assays could be a useful screening tool for DVT and might be a suitable substitute for Doppler ultrasound examinations.

Disclosure of Interest: None declared

DOI: 10.1136/annrheumdis-2018-eular.1314

\section{AB1004 OSTEOPOROSIS SCREENING IN A TERTIARY RHEUMATOID ARTHRITIS CLINIC. WHO'S SCREENING NOW?}

L. Kyi ${ }^{1}$, T. Kovitwanichkanont ${ }^{1,2}$, D. Wang ${ }^{3}$, N. Walpola ${ }^{3}$, S. Raghunath ${ }^{1,3}$ S. Pignataro ${ }^{1}$, S. Morton ${ }^{1}$, M. Leech ${ }^{1,3} .{ }^{1}$ Rheumatology, Monash Health, Melbourne; ${ }^{2}$ Sydney School of Public Health, University of Sydney, Sydney, ${ }^{3}$ Department of Medicine, Monash University, Melbourne, Australia

Background: Osteoporosis is a complication of rheumatoid arthritis (RA) due to inflammatory disease and treatment with glucocorticoids ${ }^{1}$. Screening and management of osteoporosis (OP) is shared amongst General Practitioners (GP) together with subspecialists including rheumatologists ${ }^{2}$.

Objectives: To assess the adequacy of osteoporosis screening in a tertiary RA clinic in Melbourne, and to determine where most screening is occurring.

Methods: A cross-sectional study of patients at a tertiary RA clinic was undertaken. Osteoporosis screening, therapy and related factors were evaluated. This was compared to best practice screening ACR/GIOP guidelines.

Results: 116 RA patients, $66 \%$ female (median age 58 years) were Included. OP screening occurred in $61.2 \%$ of patients with $40.5 \%$ and $20.7 \%$ performed by their rheumatologist and by the GPs respectively. The remainder $38.8 \%$ of patients recalled no recent screening.

$36.2 \%$ of patients were taking prednisolone, while $74 \%$ reported prior exposure. $58.6 \%$ of patients had prednisolone for over 3 months. Calcium or vitamin D supplementation was noted in $62 \%$ of the population. $21.6 \%$ reported a history of minimal trauma fracture and alarmingly only $10 \%$ reported currently taking antiresorptive therapy.

$47 \%$ of patients had a DEXA scan performed within the last 3 years. Of the $53 \%$ that did not have a recent DEXA scan, three quarters had indications for osteoporosis screening based on the $2010 \mathrm{ACR} / \mathrm{GIOP}$ guidelines. 35 patients had indications based on age, 11 patients based on glucocorticoid exposure and 1 patient based on history of minimal trauma fracture.

\section{Osteoporosis Screening}

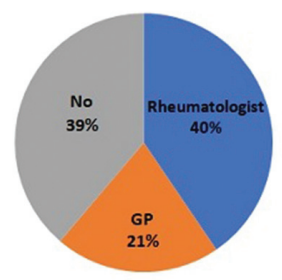

DEXA Scans

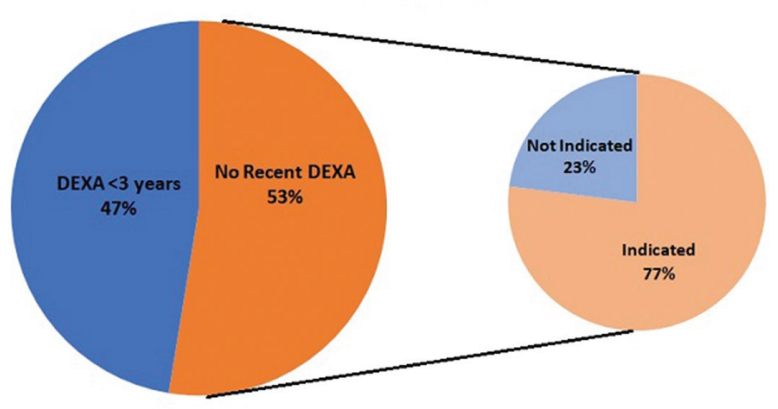

Abstract AB1004 - Figure 1

Conclusions: One third of at-risk patients in this sub-cohort are not screened for osteoporosis. More patients are currently screened for osteoporosis by their rheumatologist than their GPs. Underscreening and treatment of osteoporosis in this clinic could be addressed by clearer GP-rheumatologist shared treatment model.

\section{REFERENCES:}

[1] Lane NE, Lukert B. The science and therapy of glucocorticoid induced bone loss. Endocrinol Metab Clin North Am 1998;27: 465-83.

[2] The Royal Australian College of General Practitioners. Clinical guideline for the prevention and treatment of osteoporosis in postmenopausal women and older men. 1st edn. South Melbourne, Vic: RACGP, 2010.

Disclosure of Interest: None declared

DOI: 10.1136/annrheumdis-2018-eular.5217

\section{AB1005 RELATIONSHIP BETWEEN AUTOIMMUNITY AND OSTEOPOROSIS IN}

\section{RHEUMATOID ARTHRITIS}

M.C. Carrasco Cubero ${ }^{1}$, S.M. Rojas Herrera ${ }^{2}$, J. Malave Calzada ${ }^{2}$, P. Pérez David $^{2}$, I. Braña Abascal ${ }^{2}$, E. Chamizo Carmona ${ }^{2}{ }^{1}$ Rheumatology, CHU de Badajoz, Badajoz; ${ }^{2}$ Rheumatology, Hospital de Mérida, Mérida, Spain

Background: Osteoporosis (OP) is more prevalent in patients with rheumatoid arthritis (RA) than in the general population. Positive anti citrullinated peptide antibody (ACPA) has been related with juxta-articular OP, but their relationship with systemic OP in RA is controversial.

Objectives: To determine if RA autoantibodies (FR and ACPA) are associated with bone mineral density (BMD) in a cohort of patients with established RA diagnosed following the ${ }^{\text {ACR } 1987}$ criteria.

Methods: Observational study. We analysed the relationship between RF and/or ACPA with the DXA BMD values of the femoral neck (CF) and lumbar spine (LS) (GE LUNAR Prodigy). We perform the analysis using logistic regression, bi and multivariate models, and correlation models. The control variables were sex, body mass, age, duration of RA, prednisone and vitamin $D$.

Results: We included 294 patients with RA who had all the tests, with a mean age of $63.4( \pm 10.9)$ years and duration of RA of $9.8( \pm 7.9)$ years. There were 229 (77.9\%) women, 229 (77.9\%) positive-RF, 196 (66.7\%) positive-ACPA, 109 $(37.1 \%)$ deficient in $25-\mathrm{OH}$ cholecalciferol $(<20 \mathrm{ng} / \mathrm{ml})$ and $59(20.1)$ smoke patients. They received corticosteroids at low doses 207 (70.4\%) and suffered some bone fracture $42(14.3 \%)$ patients. In the BMD, $226(76.9 \%)$ patients had a T-score $<-1$, of who $86(27.6 \%)$ reached a T-score $<-2.5$ in LS and/or in FN. 